\title{
A Systems Analysis Framework to Optimize the Utilization of Electric Vehicles at Military Facilities
}

\author{
Michael Jerue $^{1}$, Luis Daniel Otero ${ }^{2 *}$, Senior Member, IEEE, and Aldo Fabregas ${ }^{2}$ \\ ${ }^{1}$ Operations Research, Florida Institute of Technology, Melbourne, FL, USA \\ ${ }^{2}$ Engineering Systems, Florida Institute of Technology, Melbourne, FL, USA
}

\begin{abstract}
The U.S. Department of Defense (DOD) is the world's largest consumer of petroleum, a commodity whose price volatility makes budget planning extremely difficult. A significant amount of DOD's oil consumption is attributable to its massive fleet of non-tactical vehicles - sedans, trucks and vans used for official duties at installations around the world. Federal statutes require the U.S. military to incorporate alternative-fuel vehicles, including those powered by electricity, in this fleet. This paper uses discrete event simulation built on real-world data from a fleet of sedans at an Air Force base to explain how the U.S. military can procure optimal numbers and types of electric vehicles (EVs) that will maximize financial savings while still meeting mission requirements. Output from simulated operation of the optimized fleet is then used to analyze the sensitivity of operating expense with respect to gasoline and electricity prices. This framework illuminates the path to widespread EV adoption without the time, expense and risk of committing physical assets.
\end{abstract}

Keywords-Electric vehicles; Discrete event simulation; Fleet optimization; Systems analysis

\section{INTRODUCTION AND PROBLEM STATEMENT}

For the U.S. Department of Defense (DOD), energy consumption is a troubling vulnerability. DOD is the world's single largest consumer of petroleum, and it accounts for $93 \%$ of all petroleum consumption by the federal government. [1] Although much of DOD's petroleum consumption can be attributed to its array of ships, tanks, planes and helicopters, it also has a large fleet of non-tactical vehicles that are used for simple transportation tasks at installations around the world. As of 2012, this fleet contained 195,468 vehicles, of which approximately 39,000 were sedans [2].

Two factors have conspired to make financial management of this massive fleet an extremely challenging task. First, political discord in the federal government led to "sequestration," a series of indiscriminate budget cuts that has cut DOD's budget for operations and maintenance by up to $10 \%$. Second, the volatility of the price of gasoline makes it very difficult to predict expenditures with great accuracy. A rigorous analysis, in the form of a lognormal pricing model, Kolmorogov-Smirnoff tests for normality, and an F-test for difference in variance, confirms that the price of gasoline is significantly more volatile than the price of electricity with a $\mathrm{p}$ value $<0.001$
To its credit, the federal government has recognized both the problem of petroleum addiction and the potential benefits of alternative fuels. DOD's fleet of non-tactical vehicles has been targeted for increases in efficiency. For example, Executive Order 13423 signed in 2007, requires a reduction in petroleum consumption through the use of alternative fuel vehicles. [3]. Electric vehicles (EVs) represent one of the primary subsets of alternative fuel vehicles.

The current EV market includes two classes: battery electric vehicles (BEVs) and plug-in hybrid electric vehicles (PHEVs). BEVs are purely electric (e.g., Nissan Leaf), which means they have low operating costs due to the low price of electricity and the simplified maintenance associated with electric motors. The downside of BEVs is that they are limited to a range of 60 to 90 miles, depending on driving conditions. PHEVs solve the range problem by adding a gasoline-powered generator to power the electric motor once the battery is depleted (e.g., Chevrolet Volt). By doing so, PHEVs incur higher operating costs due to the higher price of gasoline and maintenance.

The main objective of this paper is to develop a simulation modeling framework that can help decision makers identify an appropriate number of vehicles (both electric and gas-fueled) and charging stations for particular military installations. The modeling framework can be used to gain critical insights about possible alternative solutions and understand system behavior. A preliminary study was conducted using the simulation framework with real data collected from Patrick Air Force Base (PAFB) and its neighboring installation, Cape Canaveral Air Force Station (CCAFS) located near Cocoa Beach, Florida. The results from this study highlight the potential benefits of incorporating EVs into military facilities.

This paper is divided into six sections. Section II briefly describes attempted solutions in the area of simulation of EV utilization. Section III provides an overview of the systems analysis framework that will enable DOD fleet operators to optimize the incorporation of EVs. Section IV describes the simulation modeling process that is the foundation of the systems analysis framework. Section V analyzes simulation output to provide useful conclusions regarding the nature of a vehicle fleet that includes EVs. Section VI concludes the paper by describing future applications for the simulation-based framework. 


\section{ATTEMPTED SOLUTIONS}

In order to comply with mandates for alternative-fuel vehicles, DOD has deployed EVs at some of its larger bases. These projects require significant planning and investment, and they operate in an environment of uncertainty. Questions that are fundamental to fleet performance, such as "How often will the vehicles be in use?" and "How much will fuel cost?", are best answered in terms of probability distributions. This makes fleet performance an ideal situation for discrete event simulation (DES). Not surprisingly, existing research has harnessed the power of DES to study the performance of EV fleets. However, this research has focused on the potential impact of EV fleets on the electrical grid, especially in cases of widespread EV adoption [4]. Although this is a valid concern, EV fleets at DOD installations would not be large enough to have a significant impact on the grid. Furthermore, the existing research uses EV driving data generated by private civilians, whose trip characteristics (duration, distance, daily schedule) are significantly different from those of sedans used by the military [5], [6], [7]. Finally, the existing research has not attempted to optimize fleet operations. This paper moves the emphasis from the grid impact of civilian EVs to the optimization of military EV fleet operations - minimizing operating expense while satisfying a constraint on customer waiting time.

\section{OVERVIEW OF THE SYSTEMS ANALYSIS FRAMEWORK}

This paper provides a framework for modeling, optimizing, and analyzing the fleet of non-tactical vehicles at a military installation for the purpose of incorporating EVs, as outlined in the following steps:

1. Build a DES model of the current system.

2. Identify the optimal fleet under current conditions (i.e., only gasoline-powered vehicles).

3. Modify the simulation model to include electric vehicles when appropriate.

4. Identify an optimal fleet that includes EVs.

5. Compare the two optimal fleets (from steps 2 and 4) to determine whether the savings generated by the introduction of EVs are statistically significant.

6. Statistically analyze simulation output to determine characteristics of the optimal EV fleet.

7. Modify simulation variables (battery sizes, lease prices, fuel prices) to determine barriers that prevent the optimal fleet from containing only EVs.

This paper addresses steps 1 through 6 . Step 7 is the subject of ongoing research.

\section{Simulation Modeling Process}

This section describes the process that was followed to develop the simulation model. Specifically, it describes the development of the conceptual and computational models, as well as the activities performed for model verification and validation. The simulation model was constructed using the Arena simulation software package by Rockwell (student version).

\section{A. Conceptual/Specification Model}

A conceptual model serves as the foundation for a realistic simulation. The conceptual model in Figure 1 depicts the way in which a department of Vehicle Operations (VO) responds to customers' requests for vehicles. The conceptual model consists of four stages.

Stage 1: A customer contacts VO to request vehicles. Some customers submit their requests several days in advance, while others request immediate use. For the purposes of this model, the lead time of the request is irrelevant; only the vehicle use start time is significant.

Stage 2: VO assigns a vehicle to the customer. In the current system, the distance of the customer's trip does not impact the assignment process. However, once EVs are incorporated into the fleet, $\mathrm{VO}$ must ensure that an EV is suitable for the trip. $\mathrm{VO}$ relies on an algorithm that maximizes the utilization of EVs while acknowledging the range limitations of BEVs. Specifically, it will only assign BEVs to trips with distances less than the maximum range of the vehicle. If a BEV is not suitable, VO will assign a PHEV, if available. If a PHEV is not available, it will assign an internal combustion engine (ICE) vehicle.

Stage 3: The customer uses the vehicle and returns it to VO.

Stage 4: VO prepares the vehicle for the next trip. Specifically, the vehicle is refueled with gasoline, electricity or both, and any necessary maintenance is performed.

The following components were incorporated into the model:

$\begin{array}{lll}\text { - } & \text { Entities: } & \text { Customer requests for vehicles } \\ \text { - } & \text { Attributes: } & \text { Trip distance; Trip duration } \\ & \text { Resources: } & \text { Battery electric vehicles; Plug-in } \\ & \text { hybrid electric vehicles; ICE } \\ & \text { vehicles; EV charging stations } \\ \text { - } & \text { Variables: } & \text { Gasoline price; Electricity price; } \\ & & \text { Fuel efficiency; Battery size; } \\ & \text { Lease prices; Maintenance } \\ & \text { intervals }\end{array}$

Having sketched a high-level view of the system, the next step was to create a specification model in which the parameters of the system were explicitly quantified. More specifically, the parameters to be quantified were the probability distribution of vehicle usage, the prices of vehicle fuels and maintenance, and the characteristics of the system's resources.

\section{1) Vehicle Usage}

A request for vehicle usage data at PAFB and CCAFS was submitted under the Freedom of Information Act. The Air Force's response to the request included a $\log$ of 253 trips for the period from November 2011 to April 2012. The log entries showed start and end times for each trip. This information became the basis for developing a probability distribution for trip frequency. A histogram of trip start times 


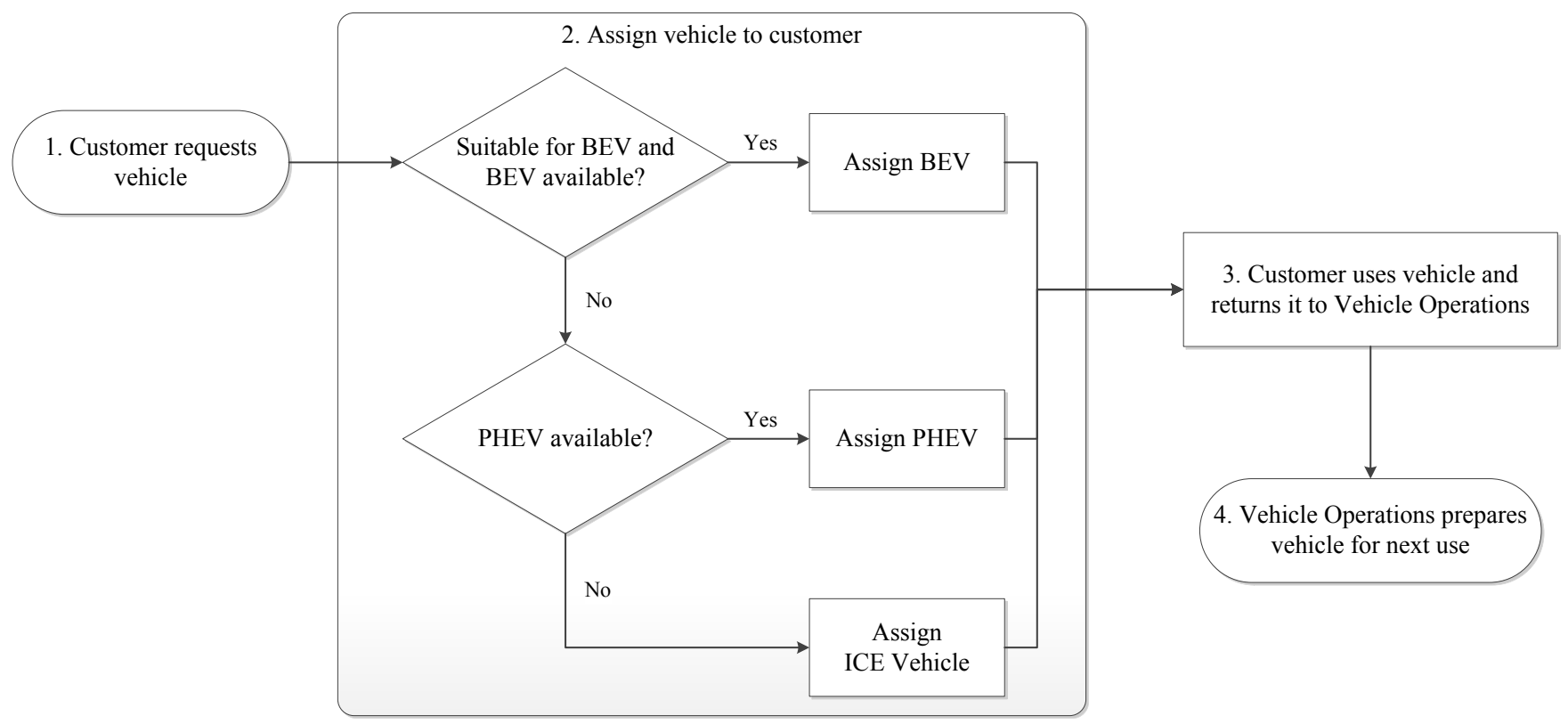

Figure 1: Conceptual Model of Vehicle Operations

showed a rush hour for requests between 8:00 AM and 10:00 AM. Goodness of fit testing confirmed that exponential distributions accurately model the arrivals of customer requests.

The trip log, however, did not show distance covered. Follow-up requests for trip mileage data revealed that this information is not maintained by the VO department at PAFB. Therefore, it became necessary to develop an assumption for the number of miles per hour of usage.

\section{2) Fuel, Maintenance and Lease Costs}

Fortunately, there is a robust record of price information for the two vehicle fuels - gasoline and electricity. In an effort to use the most relevant data available, monthly gasoline and electricity prices for Florida from June 2003 to March 2014 were retrieved from the website of the Energy Information Agency (EIA).

The Air Force did not provide information related to maintenance costs, so triangular distributions that reflect the lower costs of EV maintenance that result from the simpler characteristics of electric motors were assumed (refer to Table 1).

Regarding lease costs, it was not clear what DOD pays for vehicle leases. In the absence of this information, assumed monthly lease costs were based on those paid by private sector individuals: $\$ 100$ for BEVs, $\$ 200$ for PHEVs, and $\$ 300$ for ICE vehicles.

\section{3) Resource Characteristics}

Table 2 summarizes the vehicle resources used in the simulation.
Table 1: Summary of Probability Distributions

\begin{tabular}{|c|c|}
\hline Purpose & Distribution \\
\hline $\begin{array}{c}\text { Customer } \\
\text { Arrival }\end{array}$ & $\begin{array}{l}\text { - Non-rush hour: Exponential (interarrival } \\
\text { time with } \lambda=6 \text { hours) } \\
\text { - Rush-hour: Exponential interarrival time } \\
\text { with } \lambda=2 \text { hours) }\end{array}$ \\
\hline $\begin{array}{c}\text { Trip } \\
\text { Duration }\end{array}$ & $\begin{array}{l}\text { - } 72 \% \text { of trips last less than one day; } 28 \% \text { last } \\
\text { one day or more } \\
\text { - Day trips: Uniform ( } \min =1 \text { hour, } \max =9 \\
\text { hours) } \\
\text { - Longer trips: Uniform ( } \min =9 \text { hour, } \max = \\
72 \text { hours) }\end{array}$ \\
\hline $\begin{array}{c}\text { Trip } \\
\text { Distance }\end{array}$ & $\begin{array}{l}\text { Each trip is assigned a distance per hour of } \\
\text { usage (in miles) from the following } \\
\text { distributions: } \\
\text { - Day trips: Triangular ( } \min =1 \text {, mode }=4.5 \text {, } \\
\text { max }=21 \text { ) } \\
\text { - Longer trips: Triangular ( } \min =1, \text { mode }= \\
\text { 1.1, max }=5) \\
\text { - Trip Distance }=(\text { Trip Duration) } \times \text { (Distance } \\
\text { per hour) }\end{array}$ \\
\hline $\begin{array}{c}\text { Maintenance } \\
\text { Cost }\end{array}$ & $\begin{array}{l}\text { Varies by vehicle class: } \\
\text { - } \text { ICE: Triangular }(\min =\$ 50, \text { mode }=\$ 75, \\
\max =\$ 100) \\
\text { - } \text { PHEV: Triangular }(\min =\$ 75, \text { mode }= \\
\$ 100, \max =\$ 125) \\
\text { - } \text { BEV: Triangular }(\min =\$ 200, \text { mode }=\$ 250, \\
\max =\$ 300)\end{array}$ \\
\hline
\end{tabular}

In addition to the vehicles, there is also the electric vehicle supply equipment (EVSE), more commonly known as charging stations. EVSE ranges from high-voltage, direct current stations that can recharge a depleted battery in less than an hour to simple cords that plug into a standard 110 volt 
wall outlet. This simulation uses the most common EVSE for public installations: a 220 volt, 3.3 kilowatt charger.

Table 2: Characteristics of Vehicle Resources

\begin{tabular}{|c|c|c|}
\hline $\begin{array}{c}\text { Vehicle } \\
\text { Class }\end{array}$ & $\begin{array}{c}\text { Battery } \\
\text { Capacity }\end{array}$ & \multicolumn{1}{c|}{ Fuel Efficiency } \\
\hline BEV & $\begin{array}{c}\text { 24 kilowatt- } \\
\text { hours }\end{array}$ & 3.25 miles per kilowatt-hour \\
\hline PHEV & $\begin{array}{c}16 \text { kilowatt- } \\
\text { hours }\end{array}$ & $\begin{array}{l}\text { Under battery power: 2.25 miles } \\
\text { per kilowatt-hour } \\
\text { After battery depletion: 37 miles } \\
\text { per gallon }\end{array}$ \\
\hline ICE & N/A & 27 miles per gallon \\
\hline
\end{tabular}

\section{B. Verification and Validation}

The simulation was constructed with features to facilitate model verification. Clocks and displays show the current date, time, current gasoline and electricity prices, fleet mileages, and average expenses. Verification activities included confirming that the prices matched the original EIA data files and ensuring that customer requests were only processed during business hours at VO (Monday-Friday, 6:00 AM - 4:00 PM).

Validation primarily followed two aspects. First, the count of trips generated by the simulation was compared to the actual trip log. Second, the mileage generated by the simulation was compared to the annual average of 12,000 miles for all vehicles in the DOD fleet. In both cases, hypothesis tests at $\alpha=0.05$ showed that the simulation output was consistent with the points of reference.

\section{Optimization}

Having created a verified and validated simulation model, the next step was to employ simulation optimization. An Arena-compatible application called OptQuest allows users to run multiple replications of a simulation in order to find an optimal solution. OptQuest was set up with the objective of minimizing the monthly operating expense function. The decision variables in the optimization were the counts of BEVs, PHEVs, ICE vehicles and EV charging stations. To ensure that mission requirements were still met, a constraint on customer waiting time was imposed. Specifically, the maximum waiting time was not allowed to exceed one hour.

OptQuest was used to perform two optimizations. The first was performed in an ICE-only fleet; EVs were not an option. The goal of this optimization was to "right-size" the fleet at PAFB and CCAFS under current conditions. OptQuest concluded that the optimal number of ICE vehicles is five.

The second optimization introduced EVs as an option, allowing OptQuest to replace ICE vehicles with BEVs or PHEVs in order to reduce monthly operating expense. In this case, OptQuest reached an optimal fleet of two BEVs, two PHEVs, two ICE vehicles, and one EV charging station.

Due to computational limitations, OptQuest did not perform long-duration runs of the simulation. Therefore, it was necessary to compare the ICE-only and ICE-and-EV fleets under long-run simulations to verify that the difference in expense detected by OptQuest was statistically significant. The null and alternative hypotheses tested were:

$\mathrm{H}_{0}$ : Monthly expense for ICE-only fleet $=$ Monthly expense for ICE-and-EV fleet

$\mathrm{H}_{1}$ : Monthly expense for ICE-only fleet $\neq$ Monthly expense for ICE-and-EV fleet

Both fleets were simulated using the 130 months of EIA gasoline and electricity price data described above. Q-Q plots of the monthly expense values were used to confirm that the values follow a normal distribution, thus allowing the use of a paired-t test to compare the two sets of output. The paired-t test generated $(\$ 323.05, \$ 456.03)$ as the $95 \%$ confidence interval around the average monthly reduction in expense experienced by the optimal ICE-and-EV fleet.

Since the 95\% confidence interval around the mean difference in monthly expense does not include 0 , it can be concluded that the monthly expense of the optimal ICE-andEV fleet is lower than that of the optimal ICE-only fleet. In other words, the savings detected by OptQuest in its replacement of ICE vehicles with EVs are statistically significant over a long period of various gasoline and electricity prices.

\section{INSIGHTS ON FLEET OPERATIONS}

Having optimized the composition of an ICE-and-EV fleet and having established that it generates significant savings, the next step is to use statistical analysis of simulation output to gain insight into the nature of the fleet. Equation 1 describes the relationship between the fleet's operating expense and the prices of gasoline and electricity:

$$
\mathrm{Y}_{i}=\beta_{0}+\beta_{1} \mathrm{X}_{1, i}+\beta_{2} \mathrm{X}_{2, I}+\varepsilon_{\mathrm{I}}
$$

where,

$\mathrm{Y}_{i}=$ Expense for month $i$

$\mathrm{X}_{1, i}=$ Gasoline price for month $i$

$\mathrm{X}_{2, i}=$ Electricity price for month $i$

Multiple linear regression produces estimates for $\beta_{1}$ and $\beta_{2}$, which are interpreted as the impact on monthly expense of a change in the prices of gasoline and electricity, respectively. The results of this regression are shown in Table 3 .

Table 3: Multiple Linear Regression of Monthly Expense on Gasoline and Electricity Prices in Optimal ICE-and-EV Fleet

\begin{tabular}{|l|l|r|r|r|r|}
\hline Term & Description & Estimate & $\begin{array}{l}\text { Std } \\
\text { Error }\end{array}$ & $\begin{array}{l}\text { T- } \\
\text { value }\end{array}$ & $\begin{array}{l}\text { p- } \\
\text { value }\end{array}$ \\
\hline$\beta_{0}$ & Intercept & 1629.42 & 169.65 & 9.605 & 0 \\
\hline$\beta_{1}$ & Gasoline & 15.08 & 31.16 & 0.484 & 0.629 \\
\hline$\beta_{2}$ & Electricity & 1648.56 & 2013.06 & 0.819 & 0.414 \\
\hline
\end{tabular}

The regression shows that in an ICE-and-EV fleet, neither gasoline price nor electricity price has a statistically significant coefficient, suggesting that monthly expense is fixed relative 
to fuel prices. By contrast, a single linear regression of the ICE-only fleet's monthly expense on gasoline price showed that the coefficient of the gasoline price is statistically significant at $\alpha=0.05$. This suggests that the incorporation of EVs into the fleet insulates the monthly expense against the volatility of the price of gasoline. The interpretation of this effect is that diversifying the fuel sources to include the relatively stable electricity makes the monthly expense less variable, more fixed.

\section{CONCLUSION AND FUTURE APPLICATIONS}

This framework is a powerful tool for planners at DOD or any other agency that owns fleets of vehicles. Although the analysis presented in this paper is based on data from a particular military installation, the process can be replicated for other fleets by simply modifying the initial steps of analyzing usage data.

In addition to finding the optimal EV-and-ICE composition for a given fleet, this framework also provides the basis for quantifying barriers to widespread adoption of EVs. How much battery capacity would be required to allow an all-EV fleet? What lease price would make such a vehicle economically feasible? These questions can be answered within the given framework by modifying the simulation variables, performing the fleet optimizations, and verifying the results with new paired-t tests.

Another exciting application comes from still-emerging vehicle-to-grid (V2G) technology, which allows electricity to flow from idle EVs back into the power grid, especially at times of peak demand. As this technology becomes more widely available, V2G power flows could generate significant revenue for $\mathrm{EV}$ fleet owners. The simulation presented here can be expanded to reflect this opportunity.

\section{REFERENCES}

[1] Y.J. Dreazen, "U.S. Military Launches Alternative-Fuel Push," Wall Street Journal. May 21, 2008.

[2] Department of Defense Vehicle Fleet Presentation. http://driveoregon.org/drive-oregon-event-recap-dr-gorguinpourdepartment-defense/

[3] Executive Order 13423: "Strengthening Federal Environmental, Energy, and Transportation Management", Jan. 24, 2007. http:/www.epa.gov/greeningepa/practices/eo13423.htm

[4] Z. Darabi and M. Ferdowski, “An Event-Based Simulation Framework to Examine the Response of Power Grid to the Charging Demand of Plug-In Hybrid Electric Vehicles," IEEE Trans. Ind. Inf vol. 10, no. 1, pp. 313-322, February 2014.

[5] A. Ashtari, E. Bibeau, S. Shahidinejad, T. Molinski, "PEV Charging Profile Prediction and Analysis Based on Vehicle Usage," IEEE Trans. Smart Grid vol. 3, no. 1, pp. 341-350.

[6] G. Hill, P.T. Blythe, C. Higgins, "Deviations in Markov Chain Modeled Electric Vehicle Charging Patterns from Real World Data," $201215^{\text {th }}$ International IEEE Conf. on Intel. Trans. Sys, Anchorage, AK, Sept. 1619, 2012.

[7] Z. Lin, "Optimizing and Diversifying Electric Vehicle Driving Range for U.S. Drivers”, Transportation Science: Articles in Advance, Aug. 11, 2014 , pp. 1-15. 